\title{
Quality of Life after 10 Years of Liver Transplantation
}

\author{
Micheli F. Domingos, Júlio C. U. Coelho, Isabel R. Nogueira, Mônica B. Parolin, Jorge E. F. Matias, Alexandre C. T. de \\ Freitas, Clementino Zeni Neto, Eduardo J. B. Ramos
}

Liver Transplantation Division of the Clinical Hospital of the Federal University of Paraná and Nossa Senhora das Graças Hospital, Curitiba, Brazil

Address for correspondence: Julio Coelho, MD, $\mathrm{PhD}$, Department of Surgery, Hospital de Clinicas, Federal University of Parana, Rua General Carneiro 181- 7º andar - 80060-900 Curitiba (PR), Brazil coelhojcu@yahoo.com.br

Received: 21.06.2020 Accepted: 06.08.2020

\begin{abstract}
Aim: This study goal was to evaluate the long-term quality of life of patients who underwent cadaveric liver transplants (CLT) in two Brazilian hospitals.

Methods: Medical records of all patients who underwent CLT and survived over 10 years were revised. The international validated questionnaire Short-Form 36 was employed to assess the quality of life. Patients data were obtained from electronic medical records and study protocols.

Results: A total of 342 patients underwent CLT, of which 129 were alive and 93 fully answered the questionnaire and were included in the study. The group consisted of 62 men (66.6\%) and 31 women (33.4\%), with average age of $40.1 \pm 15.9$ years. Follow-up time was $16 \pm 4.1$ years. The most common indication of CLT was hepatic cirrhosis caused by hepatitis $\mathrm{C}$ virus, $24.7 \%$. Transplanted patients had lower scores than the general population in mental health [62.9 (95\%CI: 60.1-65.7,) vs. 74.5, p < 0.001]. In all other domains, transplanted patients had similar (emotional aspect limitiation, pain, and general health status) or superior (physical aspect limitation, social aspects, functional capacity, and vitality) scores than the general population. Functional capacity score was lower in patients with long-term complications, who were aged more than 50-years, and unemployed. Conclusions: The quality of life in patients with more than 10 years after CLT was similar or superior than the general population, except for the mental health domain.
\end{abstract}

Key words: liver transplantation - quality of life - liver cirrhosis.

Abbreviations: BMI: body mass index; CLT: cadaveric liver transplants; HBV: hepatitis B virus; HCV: hepatitis C virus; LT: liver transplantation; MELD: model for end-stage liver disease; QOL: quality of life.

\section{INTRODUCTION}

Liver transplantation (LT) is a well-established therapy for patients with end-stage chronic liver disease and acute fulminant hepatitis. Initially, LT was a high-risk procedure, with extensive mortality. However, with surgical technical advances, introduction of new immunosuppressive regimens, and improvements in the hospital care of patients, survival after transplantation has increased significantly [1-3]. Several contemporary studies have reported $90 \%$ survival after 1 year of LT, 75\% after 5 years and $70 \%$ after 10 years $[3,4]$.
With the significant improvement in survival of patients undergoing LT, several authors have begun to focus attention on quality of life (QOL) after LT $[2,3,5,6]$. Complete recovery from the procedure may take several months due to pre-LT debilitated general status and the frequent occurrence of significant complications following LT. Some patients may have recurrence of their primary disease, such as viral hepatitis, immunological diseases, and hepatocellular carcinoma. In addition, all liver transplant recipients require lifelong treatment with immunosuppressive agents and regular followup to detect and treat long-term complications.

Several studies have evaluated the various aspects of QOL after LT, such as growth and development, return to school and work, sex life and hormonal changes $[3,6]$. However, in Latin America, most of these evaluations are limited to patients undergoing LT in the short term [7-9]. To the best of our knowledge there are no Latin America studies that assessed the long-term QOL of patients who underwent LT.

The aim of the present study was to evaluate the QOL of patients who underwent cadaveric liver transplants (CLT) 
after 10 years of transplantation at the Clinical Hospital of the Federal University of Paraná and at the Nossa Senhora das Graças Hospital Curitiba, Brazil, and to identify potential factors that might be associated with impaired QOL.

\section{METHODS}

Medical records of all patients with more than 10 years LT performed at the University Hospital of the Federal University of Paraná and Nossa Senhora das Graças Hospital, Curitiba, Brazil, by the same transplantation team, were retrospectively evaluated.

Data regarding patient demographics, diagnosis, ChildPugh classification, peri-transplant clinical factors, transplant technique, graft function and complications were obtained from electronic medical records and study protocols. Before May 2006, when Model for End-Stage Liver Disease (MELD) was officially introduced in Brazil, this score was retrospectively calculated based on the exams performed on the day of the transplantation. Liver transplantation was performed using standard surgical techniques. After LT, patients were placed on standard immunosuppressive protocol consisting of tacrolimus or cyclosporine, azathioprine or mycophenolate mofetil, and prednisone.

Subjective QOL was assessed through Short-Form 36 (SF36), a generic, self-rated health survey designed to compare health status across diverse populations. This questionnaire is an internationally accepted general QOL survey validated by several authors, included for application in Brazilian population [10, 11] and is the most commonly used generic questionnaire [12]. It offers broad-spectrum questions applicable to a variety of patient groups and enables comparison between different populations.

The questionnaire includes 36 questions divided into 8 subscales on general health, physical functioning, physical role functioning, bodily pain, mental health, emotional role functioning, social functioning, and vitality, as well as aggregate scores for physical and mental health. For each question, a score was attributed. Calculation was performed according to the SF-36 questionnaire protocol, composed by the data weighting phase and raw scale calculation phase 2 , with scores ranging from 0 to 100 .

All patients who underwent LT in our Hospitals before December 31, 2008, known to be alive and whom we had a telephone number or an e-mail address were contacted. The study was duly explained to the patients. A letter with explanations, the SF-36 questionnaire, and the consent form to participate of this study were given personally or sent to the patients by e-mail. A few patients preferred to answer the questionnaire by phone or completed the questionnaire during routine medical consultation. Strict confidentiality was assured, and it was made clear that the transplant members would not have access to answers from any individual patient.

Values were expressed as average with standard deviation (average $\pm \mathrm{SD}$ ), median (minim-maxim values) and others with 95\% confidence interval (95\%CI). To evaluate the QOL in relation to the age at the transplant day, the gender, employment and late complications, the Mann-Whitney nonparametric test was applied. To analyze the QOL of the patients in relation to the average of the general population and the population of the South of Brazil, the student t test for a sample was used, comparing the averages of each SF-36 domain for the analyzed population $[10,11]$. Results with $p$ value $<0.05$ were considered as statistically significant. The statistical software SPSS 22.0 was employed to organize the charts and analyze the data.

The protocol of this study was approved by the Research Committee of the University Hospital of the Federal University of Paraná, Brazil (CAAE 91362818.7.0000.0096).

\section{RESULTS}

A total of 420 patients underwent 440 LTs in the period of September of 1991 through December of 2008. There were 342 patients who underwent CLT and 78 patients who were subjected to living donor LT. Of the patients who underwent CLT, 129 (37.7\%) were alive on December 31, 2018 (Fig. 1). In addition to the patients who were subjected to living donor LT and the ones who died, we excluded from the study patients who had no follow-up in our hospital $(n=29)$, who opted not to participate in the research or did not answer all the questions $(n=5)$ and who had incomplete medical records $(n=2)$. The remaining 93 patients were subjected to the study.

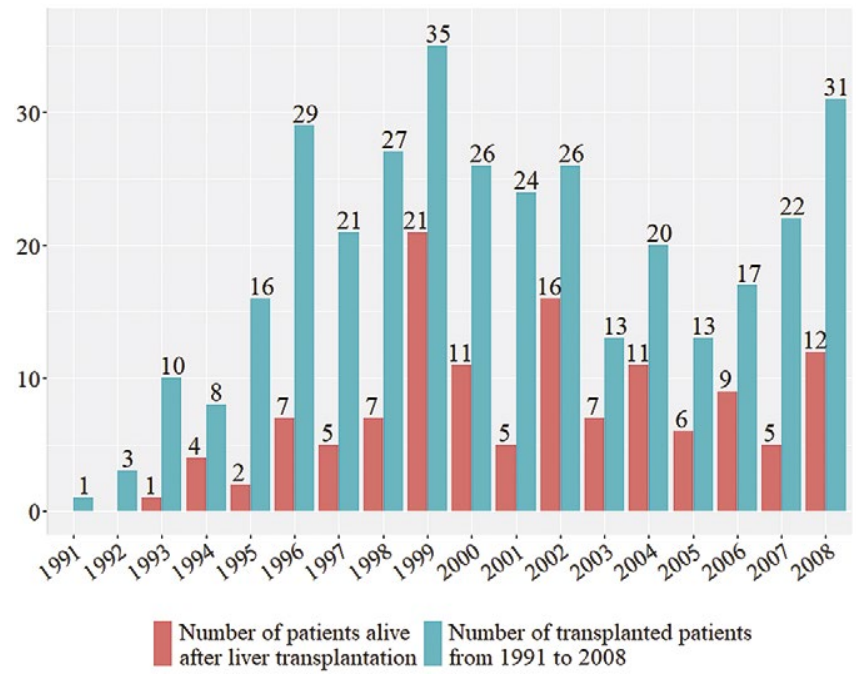

Fig. 1. Number of transplanted patients from 1991 to 2008 and the number of those who were alive until 2018 and have participated in the study.

Clinical and epidemiological characteristics of the 93 patients who have participated in the study are shown in Table I. There were 62 men (66.6\%). The average age was $40.1 \pm 15.9$ years (9-66) at the time of transplantation, with average body mass index (BMI) of $24.5 \pm 4.5 \mathrm{Kg} / \mathrm{m}^{2}\left(14.3-40.1 \mathrm{Kg} / \mathrm{m}^{2}\right)$ for $\mathrm{n}=86$. At the time of the study the average age was $56 \pm 15.1$ years (24-82). The average follow-up time was $16 \pm 4.1$ years (10-25).

Child-Pugh classification and MELD score were used to determine the severity of the liver disease. MELD ranged from 9 to 40 points $(n=74)$, with an average of $16.9 \pm 5.1$ and median of 16 points (Table I). For this purpose, additional points were not added to the MELD score of patients with associated hepatocellular carcinoma. Of the 83 patients who had the classification of Child-Pugh available in the medical records, 14 (17\%) were class A, 49 (59\%) class B and 20 (24\%) class C. 
Table I. Demographic data and indications for liver transplant

\begin{tabular}{|c|c|}
\hline \multicolumn{2}{|l|}{ Characteristics of transplanted patients, $n=93$} \\
\hline Age at the time of transplantation (years) ${ }^{\#}$ & $40.1 \pm 15.9$ \\
\hline Age at the time of study analysis (years) ${ }^{\#}$ & $56 \pm 15.1$ \\
\hline \multicolumn{2}{|l|}{ Gender, N (\%) } \\
\hline Male & $62(66.6)$ \\
\hline Follow-up time (years) ${ }^{\wedge}$ & $16(10-25)$ \\
\hline $\operatorname{BMI}\left(\mathrm{kg} / \mathrm{m}^{2}\right)^{\#}, \mathrm{n}=86$ & $24.5 \pm 4.5$ \\
\hline \multicolumn{2}{|l|}{ Child-Pugh classification, $n=83, N(\%)$} \\
\hline A & $14(17)$ \\
\hline $\mathrm{B}$ & $49(59)$ \\
\hline $\mathrm{C}$ & $20(24)$ \\
\hline MELD score $^{\#}, \mathrm{n}=74$ & $16.9 \pm 5.1$ \\
\hline \multicolumn{2}{|l|}{ Blood type, $\mathrm{n}=79, \mathrm{~N}(\%)$} \\
\hline A & $26(33)$ \\
\hline B & $8(10.1)$ \\
\hline $\mathrm{AB}$ & $4(5)$ \\
\hline $\mathrm{O}$ & $41(51.9)$ \\
\hline \multicolumn{2}{|l|}{ Indications for liver transplantation, $\mathrm{n}=93$} \\
\hline Hepatitis $\mathrm{C}$ virus & $23(24.7)$ \\
\hline Hepatitis B virus & $17(18.3)$ \\
\hline Autoimmune hepatitis & $16(17.2)$ \\
\hline Alcoholic cirrhosis & $15(16.2)$ \\
\hline Cryptogenic cirrhosis & $6(6.4)$ \\
\hline Primary sclerosing cholangitis & $4(4.3)$ \\
\hline Metabolic cirrhosis* & $3(3.2)$ \\
\hline Budd Chiari disease & $3(3.2)$ \\
\hline Primary biliary cirrhosis & $2(2.2)$ \\
\hline Others ${ }^{* *}$ & $4(4.3)$ \\
\hline
\end{tabular}

Metabolic cirrhosis*: Wilson's disease $(\mathrm{n}=1)$; Alpha 1 antitrypsin deficiency $(n=2)$. Others ${ }^{* *}$ : Giant hepatic adenoma $(n=1)$; Alagille Syndrome $(n=1)$; steatohepatitis $(n=1)$; Familial amyloid polyneuropathy $(n=1)$. *: values expressed as average \pm standard deviation; ${ }^{\wedge}$ : values expressed as median (min-max). Observation: hepatocarcinoma associated $(n=11)$.

The most common indications for cadaveric liver transplantation (CLT) were liver cirrhosis caused by hepatitis C virus (HCV) and hepatitis B virus (HBV), representing $24.7 \%$ and $18.3 \%$ of causes, respectively. The remaining indications are listed in Table I. All patients with alcoholic cirrhosis had abstained from alcohol for at least 6 months prior to LT.

Early postoperative complications occurred within 30 days of CLT or until patient discharge and were observed in 52 patients (66\%). Acute liver rejection was the main complication $(34.6 \%)$ and pulse therapy was used as treatment in $88.8 \%$ of the cases ( 16 out of 18 patients).

Late postoperative complications were defined as any complication that occurred from the $30^{\text {th }}$ postoperative day until the day of the last evaluation for data collection for the present manuscript. Seventy patients $(75.3 \%)$ had one or more complications. Of 23 patients with HCV hepatitis who underwent LT, 18 had viral recurrence (78\%). Only 6 patients with HCV recurrence were treated with ribavirin.
Late complications were divided into four categories: cardiovascular and renal diseases $(n=35$; e.g., arterial hypertension, renal dysfunction), hepatitis $\mathrm{C}$ virus recurrence $(n=18)$, biliary duct stricture and other complications $(n=22$; e.g., rejection, abdominal hernia, lymphoma). Five patients developed de novo malignancy after LT, three posttransplant lymphoproliferative diseases, 1 prostate carcinoma, and 1 skin cancer. All patients responded well to treatment, with no tumor recurrence. No hepatocellular carcinoma recurrence or de novo was recorded in the present study, which included only patients who survived more than 10 years after LT. Twentythree patients $(24.7 \%)$ had no late complications. Patients with late complications needed more posttransplant hospital readmissions than patients without late complications $(4.2 \pm 0.5$ vs. $1.3 \pm 0.1 ; \mathrm{p}=0.01)$.

Retransplantation was performed in 5 patients $(5.4 \%)$ due to chronic rejection $(n=3)$ and hepatic artery thrombosis $(n=2)$. The surgery was performed $2.9 \pm 3.5$ years after the initial transplant. One patient needed a third transplant, performed three days after the second, due to hepatic artery thrombosis.

In comparison with data obtained from the general Brazilian population constituted of 12,423 randomly selected Brazilian men and women aged 18 years old or more from urban and rural areas of all five Brazilian regions who completed the SF36 questionnaire (Social Dimensions of Inequalities Study), our study showed some important findings. The data were expressed as average with $95 \% \mathrm{CI}$ in transplanted patients vs. average of general Brazilian population. Transplanted patients had lower scores than the general population in mental health [62.9 (95\%CI: 60.1-65.7,) vs. 74.5, p<0.001]. In all other domains, transplanted patients had similar (emotional aspects, pain, and general health status) or superior (physical aspects, social aspects, functional capacity and vitality) scores than the general population (Table II).

When compared with the population of the south Brazilian region, transplanted patients had also lower scores in mental health [62.9 (95\%CI: 60.1-65.7) vs. 73.8, p<0.001] (Table II). In all other domains, transplanted patients had a better quality of life, except in the general health status [69.3 (95\%CI: 65.8-73) vs. $71.1, \mathrm{p}=0.307]$, in which there was no difference between the two groups.

Transplanted patients were also divided into groups and quality of life compared according to age, gender, and posttransplant employment (Table III) and occurrence of late complications (Table IV). These data were expressed in average $\pm S D$. Functional capacity score was better in transplanted patients with $\leq 50$ years years of age than in patients with $>50$ years $(92.8 \pm 10.8$ vs. $83.4 \pm 23.7, \mathrm{p}=0.026)$ and in employed than in non-employed $(94.9 \pm 9.3$ vs. $85 \pm 20$, $\mathrm{p}=0.01$ ) (Table III). The social aspects score was lower for females than males $(84.7 \pm 18.4$ vs. $91.1 \pm 19.8, \mathrm{p}=0.018)$ (Table III).

Late complications showed a significant association with some aspects of quality of life. Functional capacity was worse in patients that had cardiovascular and/or renal complications and HCV recurrence than in patients who had no complications (Table IV). 
Table II. Comparation of quality of life between transplanted patients vs. the general Brazilian population (BP) and vs. South of BP

\begin{tabular}{lccccc}
\hline SF-36 Domains & $\begin{array}{c}\text { Transplanted patients } \\
(\mathrm{n}=93)(95 \% \mathrm{CI})\end{array}$ & $\begin{array}{c}\text { General BP } \\
(\mathrm{n}=12,423)\end{array}$ & $\mathrm{p}$ & $\begin{array}{c}\text { South of BP } \\
(\mathrm{n}=755)\end{array}$ & $\mathrm{p}$ \\
\hline EA & $81.3(73.7-88.9)$ & 81.7 & 0.922 & 70 & 0.004 \\
PA & $86.6(80.4-92.8)$ & 77.5 & 0.005 & 74.7 & $<0.001$ \\
SA & $88.9(85-93)$ & 83.9 & 0.014 & 78.3 & $<0.001$ \\
FC & $89.9(86.5-93.3)$ & 75.5 & $<0.001$ & 82.4 & $<0.001$ \\
Pain & $80.3(75.6-84.9)$ & 76.7 & 0.132 & 67.5 & $<0.001$ \\
GHS & $69.3(65.8-73)$ & 70.2 & 0.609 & 71.1 & 0.307 \\
MH & $62.9(60.1-65.7)$ & 74.5 & $<0.001$ & 73.8 & $<0.001$ \\
VT & $80.7(76.8-84.7)$ & 71.9 & $<0.001$ & 66.8 & $<0.001$ \\
\hline
\end{tabular}

Note: EA: emotional aspects; PA: physical aspects; SA: social aspects; FC: functional capacity; GHS: general health status; $\mathrm{MH}$ : mental health; VT: vitality

Table III. Comparative analysis of SF-36 domains of transplanted patients according to age, gender and employment

\begin{tabular}{lccccccccc}
\hline $\begin{array}{l}\text { SF-36 } \\
\text { Domains }\end{array}$ & $\begin{array}{c}\text { Age } \leq 50 \text { years } \\
(\mathrm{n}=64)\end{array}$ & $\begin{array}{c}\text { Age }>50 \text { years } \\
(\mathrm{n}=29)\end{array}$ & $\mathrm{p}$ & $\begin{array}{c}\text { Female } \\
(\mathrm{n}=31)\end{array}$ & $\begin{array}{c}\text { Male } \\
(\mathrm{n}=62)\end{array}$ & $\mathrm{p}$ & $\begin{array}{c}\text { Non- Employed } \\
(\mathrm{n}=50)\end{array}$ & $\begin{array}{c}\text { Employed } \\
(\mathrm{n}=43)\end{array}$ & $\mathrm{p}$ \\
\hline EA & $78.5 \pm 39.2$ & $87.5 \pm 30.9$ & 0.373 & $73.6 \pm 41.7$ & $85.2 \pm 33.9$ & 0.130 & $80.9 \pm 37.5$ & $81 \pm 37.2$ & 0.991 \\
PA & $87.5 \pm 29.5$ & $84.5 \pm 31.6$ & 0.576 & $80.6 \pm 33.4$ & $89.5 \pm 28.1$ & 0.149 & $83.3 \pm 32.3$ & $89.5 \pm 27.9$ & 0.303 \\
SA & $91.2 \pm 15.5$ & $84 \pm 25.8$ & 0.517 & $84.7 \pm 18.4$ & $91.1 \pm 19.8$ & 0.018 & $85.7 \pm 23.6$ & $92.7 \pm 13.1$ & 0.396 \\
FC & $92.8 \pm 10.8$ & $83.4 \pm 23.7$ & 0.026 & $87.9 \pm 16.5$ & $90.9 \pm 16.5$ & 0.287 & $85 \pm 20$ & $94.9 \pm 9.3$ & 0.01 \\
Pain & $81.7 \pm 21$ & $76.9 \pm 25.8$ & 0.482 & $73.2 \pm 26.1$ & $83.8 \pm 19.9$ & 0.080 & $74.9 \pm 26.4$ & $85.7 \pm 16.3$ & 0.068 \\
GHS & $69.6 \pm 17$ & $68.5 \pm 16.6$ & 0.701 & $71.2 \pm 18.3$ & $68.4 \pm 16.2$ & 0.215 & $67.6 \pm 16.2$ & $70.7 \pm 17.9$ & 0.266 \\
MH & $62.1 \pm 13.7$ & $64.7 \pm 13$ & 0.265 & $63.7 \pm 11.9$ & $62.5 \pm 14.4$ & 0.990 & $63.1 \pm 16$ & $62.7 \pm 10.5$ & 0.131 \\
VT & $82.1 \pm 18.2$ & $77.7 \pm 21.6$ & 0.366 & $76.3 \pm 19.9$ & $83 \pm 18.8$ & 0.069 & $77.5 \pm 21.9$ & $83.9 \pm 15.9$ & 0.190 \\
\hline
\end{tabular}

For abbreviations see Table II

Table IV. Comparative analysis of SF-36 domains of transplanted patients according to absence or presence of late complications

\begin{tabular}{lccccccc}
\hline SF-36 Domains & $\begin{array}{c}\text { Absence of late } \\
\text { complications } \\
(\mathrm{n}=23)\end{array}$ & $\begin{array}{c}\text { Cardiovascular and } \\
\text { renal complications } \\
(\mathrm{n}=35)\end{array}$ & $\mathrm{p}$ & $\begin{array}{c}\text { HCV recurrence } \\
(\mathrm{n}=18)\end{array}$ & $\mathrm{p}$ & \multicolumn{2}{c}{$\begin{array}{c}\text { Biliary duct } \\
\text { complications } \\
(\mathrm{n}=18)\end{array}$} \\
\hline EA & $83 \pm 37.8$ & $79.6 \pm 39.4$ & 0.669 & $73.4 \pm 41.3$ & 0.432 & $89.2 \pm 31.5$ & 0.578 \\
PA & $93.5 \pm 22.9$ & $85.7 \pm 31.7$ & 0.256 & $83.8 \pm 30.5$ & 0.302 & $90.3 \pm 28.6$ & 0.779 \\
SA & $92.9 \pm 11.2$ & $87.9 \pm 23.2$ & 0.916 & $84.6 \pm 27.4$ & 0.685 & $88.2 \pm 19.4$ & 0.755 \\
FC & $94.1 \pm 9.7$ & $86.1 \pm 21.7$ & 0.040 & $79.4 \pm 29.2$ & 0.032 & $93.9 \pm 9.2$ & 0.424 \\
Pain & $83.5 \pm 21.8$ & $78.2 \pm 21.8$ & 0.326 & $79.4 \pm 23.5$ & 0.626 & $80.5 \pm 28.0$ & 0.941 \\
GHS & $68.3 \pm 17$ & $69.9 \pm 16.4$ & 0.886 & $67.3 \pm 19.2$ & 0.745 & $72.7 \pm 14.7$ & 0.344 \\
MH & $63.5 \pm 12.4$ & $65.7 \pm 10.6$ & 0.454 & $64.5 \pm 12.1$ & 0.725 & $63.1 \pm 15.8$ & 0.638 \\
VT & $87.2 \pm 16.9$ & $80.6 \pm 16.6$ & 0.053 & $76.2 \pm 20.9$ & 0.075 & $79.2 \pm 21.2$ & 0.092 \\
\hline
\end{tabular}

For abbreviations see Table II

\section{DISCUSSION}

There is a dearth of data on long-term survival and QOL after LT in Latin America. The few publications on this subject is limited to patients with follow-up less than 5 years after LT [7-9]. The present study includes patients who were subjected to CLT with at least 10 -year survival. Our $37.7 \%$ survival for patients with more than 10 years after CLT is lower than that of most American and European institutions. Our average follow-up time was 16 years.

Presently, 10-year survival rate of patients subjected to LT in the United States and Europe is 50 to $60 \%[2,3,5,6,12,13]$. This difference is possibly due to several medical limitations of developing countries, such as Brazil, mainly shortage of appropriate hospital resources and patients' economic and cultural differences.

The outcome of LT has improved dramatically over the past two decades in terms of reducing the morbidity and mortality. It is also of paramount importance to determine whether the LT is able to restore the QOL $[4,13]$. Several studies have evaluated the various aspects of QOL after LT, such as growth and development, return to school and work, sex life and hormonal changes, both in short-term and long-term after the transplant $[3,14-19]$. These studies have documented a significant QOL improvement, with most patients returning to normal life. 
Several studies demonstrated that QOL improves and remains stable over the years after transplantation but does not reach the level of the general population in one domain, namely physical activity $[1-3,5,12]$. This may be due to the presence of comorbidities, side-effects of immunosuppressors, and recurrence of liver disease in some patients.

There is, however, little information on the long-term QOL in patients after LT in Latin America [7-9, 14-16]. Long-term follow-up for LT has been defined as at least 5 years duration based on average, median or final recorded time of follow-up [3]. Our report presents the findings of a single-transplant team study of QOL in patients with more than 10 years after successful LT.

The World Health Organization Committee for QOL defined that QOL is a "multidimensional construct that is affected by physical health, psychological health, functional status, social relationships, personal beliefs" [20]. The method of QOL evaluation used in our study was the SF-36, which has been validated in several countries, including in Brazil. This QOL questionnaire was developed by Ware and Sherbourne [10] in the English language and translated and validated in Brazil by Ciconelli et al. [11] in 1999. It assesses 8 domains on general health, functional capacity, physical aspects, bodily pain, mental health, emotional aspects, social functioning, and vitality.

Our study showed that mental health was the only QOL domain lower in CLT patients than the general Brazilian population [21] or the population of the southern region of the country [22]. In all other QOL domains, CLT had similar or superior scores than the general or southern population of Brazil. A possible explanation for mental health status to be the only QOL domain that was reduced in our study may be related to the distress and fear reported by our patients of depending exclusively on the Federal Brazilian Government to obtain expensive medications (e.g. immunosuppressants, antivirals), and to perform surgical procedures to treat potential complications for the rest of their lives. Other authors have also reported lower mental health scores following LT, possibly due to fear of losing disability or Medicaid benefits, adverse effects of medications, recurrence of liver disease, and other potential complications $[23,24]$.

Several studies demonstrated that the socioeconomic status, such as marital status, education level, social support, income, profession, and employment are crucial factors that influence QOL after LT $[3,12,25]$. Since Brazil is a large country with enormous socioeconomic and cultural differences between the Brazilian regions, we considered that it was important to compare QOL of the CLT patients not only with that of the general population, but also with that of the south Brazilian region, where our hospitals are located. Another important aspect that should be considered is the gratitude that most patients have for the success of the transplant. This may have contributed to a positive result in QOL of our study.

Contrary to our findings, the studies from the transplant centers at the University of California, USA and at the University of Cambridge, England, showed no mental health domain difference between transplanted patients and the general population $[1,5]$. These two studies have also demonstrated that physical aspects domain was inferior in transplanted patients. Our study as well as that of Drent et al.
[26] showed no reduction in physical aspects in transplanted patients. The QOL evaluation is difficult and conflicting results may be due to different questionnaires employed and distinct patients' expectation. QOL of some patients is already diminished prior to the LT due to the physical, emotional, and social limitations imposed by the liver disease. Therefore, it is not surprising that many patients may compare positively their present QOL with the one they had before the LT.

Similar to our findings, several studies demonstrated no reduction in other QOL domains assessed (general health, physical aspects, bodily pain, emotional aspects, social aspects and vitality) in transplanted patients as compared to the general population $[1,5,12]$.

Social factors, such as marital status, family support, and employment are important factors to improve QOL following LT $[12,28]$. These factors help to restore the functional role of the patients in society. Similar to Desai et al. [1] and Zahn et al. [27], we observed that the functional capacity score was better in LT recipients with $\leq 50$ years of age and in patients employed after the transplant. We also recorded that the social aspect score was lower in females than in males .

Presence of long-term complications following LT, such as $\mathrm{HCV}$ recurrence, cardiovascular complications, and renal complication, may impact QOL of LT recipients [12, 28]. Most patients with these severe complications may need repeated hospital readmissions for evaluation and treatment. In addition to the physical suffering, these patients may experience anxiety, stress, depression, and expectation reduction. These important changes may contribute to QOL reduction. As previously demonstrated by other authors, the present study showed a reduced functional capacity in patients with these late complications $[12,23,24,28]$.

Mental health domain reduction observed in our transplanted patients is an important finding. Transplanted patients should have routine mental health evaluation and therapeutic measures instituted when mental health changes are recognized. A multidisciplinary approach with psychological treatment and social intervention may be helpful for rehabilitating these patients.

The major strength of our study is the large number of patients with more than 10 years of survival after liver transplantation. In addition, the percentage of living patients who have participated in the study is high.

The major limitation of our study is the retrospective evaluation of the data of our patients. This is minimized because all medical and surgical procedures were coordinated and supervised by the same transplant team and the data were retrieved from electronic medical records and study protocols.

\section{CONCLUSIONS}

In our study QOL in patients with more than 10 years after LT is similar or superior than in the general population, except for the mental health domain which is inferior.

Conflicts of interest: None to declare.

Authors' contribution: M.F.D. and J.C.U.C. conceived the study R.S.B., and H.D.V.B. performed the statistical analysis. J.C.U.C., M.F.D 
and I.R.N. interpreted the data and drafted the manuscript; M.F.D., and J.C.U.C. approved the final version and revised the manuscript.

\section{REFERENCES}

1. Desai R, Jamieson NV, Gimson AE, et al. Quality of life up to 30 years following liver transplantation. Liver Transpl 2008;14:1473-1479. doi:10.1002/lt.21561

2. Sullivan KM, Radosevich DM, Lake JR. Health-related quality of life: Two decades after liver transplantation. Liver Transpl 2014;20:649-654. doi:10.1002/lt.23855

3. Yang LS, Shan LL, Saxena A, Morris DL. Liver transplantation: A systematic review of long-term quality of life. Liver Int 2014;34:12981313. doi:10.1111/liv.12553

4. Jain A, Reyes J, Kashyap R, et al. Long-term survival after liver transplantation in 4,000 consecutive patients at a single center. Ann Surg 2000;232:490-500. doi:10.1097/00000658-200010000-00004

5. Duffy JP, Kao K, Ko CY, et al. Long-term patient outcome and quality of life after liver transplantation. Ann Surg 2010;252:652-661. doi:10.1097/ SLA.0b013e3181f5f23a

6. Belle SH, Porayko MK, Hoofnagle JH, Lake JR, Zetterman RK. Changes in quality of life after liver transplantation among adults. Liver Transpl Surg 1997;3:93-104. doi:10.1002/lt.500030201

7. Sanchez C, Eymann A, De Cunto C, D’Agostino D. Quality of life in pediatric liver transplantation in a single-center in South America. Pediatr Transplant 2010;14:332-336. doi: 10.1111/j.13993046.2009.01225.x

8. Benítez C, Wolff R. Current status and future challenges of liver transplantation programs in Chile. Liver Transpl 2018;24:1757-1761. doi:10.1002/lt.25332

9. Hernández-Ruiz V, García-Lara JMA, Zamudio-Rodríguez A, GarcíaJuárez I, Avila-Funes JÁ. Liver transplantation in Mexican older adults: A comparative single-center study. Rev Gastroenterol Mex 2019;84:455460. doi:10.1016/j.rgmx.2018.09.003

10. Ware JE Jr, Sherbourne CD. The MOS 36-item short-form health survey (SF-36) I. Conceptual framework and item selection. Med Care 1992;30:473-483.

11. Ciconelli RM, Ferraz MB, Santos W, Meinão I, Quaresma MR. Tradução para a língua portuguesa e validação do questionário genérico de avaliação de qualidade de vida SF-36 (Brasil SF-36). Rev Bras Reumatol 1999;39(3):143-150.

12. Onghena L, Develtere W, Poppe C, et al. Quality of life after liver transplantation: State of the art. World J Hepatol 2016;8:749-756. doi:10.4254/wjh.v8.i18.749

13. Carr AJ, Higginson IJ. Are quality of life measures patient centred? BMJ 2001;322:1357-1360. doi:10.1136/bmj.322.7298.1357

14. Coelho JCU, de Freitas ACT, Matias JEF, Pissaia A Jr, de Godoy JL, Zeni JOV. Sexual dysfunction in males with end-stage liver disease: Partial recovery after liver transplantation. J Liver Dis Transplant 2014;3:1-4. doi:10.4172/2325-9612.1000122
15. Coelho JCU, Matias JEF, Zeni Neto C, de Godoy JL, Canan Junior LW, Jorge FMF. Função sexual de homens submetidos a transplante hepático. Rev Assoc Med Bras 2003;49:413-417. doi:10.1590/S0104-42302003000400033

16. Parolin MB, Rabinovitch I, Urbanetz AA, Scheidemantel C, Cat ML, Coelho JCU. Impact of successful liver transplantation on reproductive function and sexuality in women with advanced liver disease. Transplant Proc 2004;36:943-944. doi:10.1016/j.transproceed.2004.03.124

17. Castro GRA, Coelho JCU, Parolin MB, Matias JEF, de Freitas ACT. Insulin-like growth factor I correlates with MELD and returns to normal level after liver transplantation. Ann Transplant 2013;18:57-62. doi:10.12659/AOT.883819

18. Nitsche R, Coelho JCU, de Freitas ACT, Zeni Neto C, Martins E. Testosterone changes in patients with liver cirrhosis before and after orthotopic liver transplantation and its correlation with MELD. Arq Gastroenterol 2014;51:59-63. doi:10.1590/s0004-28032014000100012

19. Zacharias BT, Coelho JCU, Parolin MB, Matias JEF, de Freitas ACT, de Godoy JL. Hypothalamic-pituitary-gonadal function in men with liver cirrhosis before and after liver transplantation. Rev Col Bras Cir 2014;41:421-425. doi:10.1590/0100-69912014006007

20. World Health Organization Committee. WHOQOL measuring quality of life. Geneva, Switzerland: World Health Organization. 1997;16-17. Available at:https://apps.who.int/iris/handle/10665/63482

21. Laguardia J, Campos MR, Travassos C, Najar AL, Anjos LA, Vasconcellos MM. Brazilian normative data for the short form 36 questionnaire, version 2. Rev Bras Epidemiol 2013;16:889-897. doi:10.1590/s1415790x2013000400009

22. Cruz LN, Fleck MP, Oliveira MR, et al. Health-related quality of life in Brazil: Normative data for the SF-36 in a general population sample in the south of the country. Cien Saude Colet 2013;18:1911-1921. doi:10.1590/s1413-81232013000700006

23. Burra P, Germani G. Long-term quality of life for transplant recipients. Liver Transpl 2013;19 (Suppl 2):S40-S43. doi:10.1002/lt.23725

24. De Bona M, Ponton P, Ermani M, et al. The impact of liver disease and medical complications on quality of life and psychological distress before and after liver transplantation. J Hepatol 2000;33:609-615. doi:10.1016/S0168-8278(00)80012-4

25. Bownik H, Saab S. Health-related quality of life after liver transplantation for adult recipients. Liver Transpl 2009;15Suppl 2:S42-S49. doi:10.1002/ 1t.21911

26. Drent G, Graveland CW, Hazenberg BP, Haagsma EB. Quality of life in patients with familial amyloidotic polyneuropathy long-term after liver transplantation. Amyloid 2009;16:133-141. doi:10.1080/13506120903090726

27. Zahn A, Seubert L, Jünger J, et al. Factors influencing long-term quality of life and depression in German liver transplant recipients: A single-centre cross-sectional study. Ann Transplant 2013;18:327-335. doi:10.12659/AOT.883962

28. Kousoulas L, Neipp M, Barg-Hock H, et al. Health-related quality of life in adult transplant recipients more than 15 years after orthotopic liver transplantation. Transpl Int 2008:21:1052-1058. doi:10.1111/j.14322277.2008.00733.x 